Journal of Mathematics and Statistics 8 (1): 111-113, 2012

ISSN 1549-3644

(C) 2012 Science Publications

\title{
On the Derived Subgroups of Some Finite Groups
}

\author{
${ }^{1}$ Rashid, S., ${ }^{1}$ N.H. Sarmin, \\ ${ }^{2}$ A. Erfanian and ${ }^{1}$ N.M. Mohd Ali \\ ${ }^{1}$ Department of Mathematics, Faculty of Science and Ibnu Sina \\ Institute for Fundamental Science Studies, \\ University Technology Malaysia, 81310 UTM Johor Bahru, Johor, Malaysia \\ ${ }^{2}$ Department of Pure Mathematics, School of Mathematical Sciences, \\ Centre of Excellence in Analysis on Algebraic Structures, \\ Ferdowsi University of Masshad, Masshad, Iran
}

\begin{abstract}
Problem statement: In this study we focus on the derived subgroup of nonabelian 3generator groups of order $\mathrm{p}^{3} \mathrm{q}$, where $\mathrm{p}$ and $\mathrm{q}$ are distinct primes and $\mathrm{p}<\mathrm{q}$. Our main objective is to compute the derived subgroup for these groups up to isomorphism. Approach: In a group G, the derived subgroup $G^{\prime}=[G, G]$ is generated by the set of commutators of $G, K(G)=\{[x, y] \mid x, y \in G\}$ and introduced by Dedekind. The relations of the group are used to compute the derived subgroup. Results: The results show that the derived subgroup of nonabelian 3-generator groups of order $\mathrm{p}^{3} \mathrm{q}$ is a cyclic group, $\mathrm{Q}_{8}$ or $\mathrm{A}_{4}$. Conclusion/Recommendations: The problem can be considered to compute the derived subgroup of these groups without the use of the relations.
\end{abstract}

Key words: Derived subgroup, sylow theorems, finitely generated group

\section{INTRODUCTION}

Miller (1898) introduced the derived subgroup $\mathrm{G}^{\prime}$ of a group $\mathrm{G}$ as the subgroup generated by $\mathrm{K}(\mathrm{G})=$ $\{[x, y] \mid x, y \in G\}$, the set of commutators of $G$. According to Miller, commutators $[\mathrm{x}, \mathrm{y}]$ were introduced by Dedekind a few years earlier. Commutators can act as a tool in all of group theory. For example, commutators can be used to compute Schur multiplier, Schur multiplier of a pair and nonabelian tensor squares of groups.

Basic definitions and theorems: Includes some definitions and results on the derived subgroups of nonabelian groups.

Definition 1: Hungerford (1997) let $G$ be a group and $X$ a subset of $G$. Let $\left\{\mathrm{H}_{\mathrm{i}} \mid \mathrm{i} \in \mathrm{I}\right\}$ be the family of all subgroups of $\mathrm{G}$ which contains $\mathrm{X}$. Then $\cap \mathrm{H}_{\mathrm{i}}$ is called the subgroup of $G$ generated by the set $\mathbf{X}$ and is denoted by $\langle\mathrm{X}\rangle$.

Theorem 2: Hungerford (1997) let $G$ be a group and $\mathrm{X}$ a non empty subset of $\mathrm{G}$. Then the subgroup $\langle\mathrm{X}\rangle$ generated by $\mathrm{X}$ consists of all finite product finite product $\mathrm{a}_{1}{ }_{1}{ }_{1} \mathrm{a}_{2}{ }_{2}{ }_{2} \mathrm{a}_{3}{ }^{\mathrm{n}} \ldots \mathrm{a}_{\mathrm{t}} \mathrm{n}^{\mathrm{n}}\left(\mathrm{a}_{\mathrm{i}} \in \mathrm{X}, \mathrm{n}_{\mathrm{i}} \in \mathrm{Z}\right)$. In particular for every $a \in G,\langle a\rangle=\left\{a^{n} \mid n \in Z\right\}$.
Definition 3: Hungerford (1997) let $G$ is a group. The subgroup of $G$ generated by the set $\left\{x^{-1} y^{-1} x y \mid x, y \in\right.$ $\mathrm{G}$ \} is called the derived subgroup of $\mathrm{G}$ and denoted by $\mathrm{G}^{\prime}$.

Let $\mathrm{G}$ be a group and let $\mathrm{G}^{(1)}$ be $\mathrm{G}^{\prime}$. Then for $\mathrm{i} \geq 1$, define $G^{(i)}=G^{(i-1) 巴}$. The notation $G^{(i)}$ is called the ith derived subgroup of $\mathrm{G}$. This gives a sequence of subgroups of $G$, each normal in preceding one: $G>G^{(1)}$ $>G^{(2)}>\cdots$. Actually each $G^{(i)}$ is a normal subgroup of G.

Burnside (1911) classified all finite groups of order $\mathrm{p}^{2} \mathrm{q}$ and Western (1898) obtained the classification of groups of order $\mathrm{p}^{3} \mathrm{q}$, where $\mathrm{p}$ and $\mathrm{q}$ are distinct primes.

The classification of all nonabelian 2-generator groups of order $\mathrm{p}^{3} \mathrm{q}$ is given in the following theorem.

Theorem 4: Western (1898) Let G be a nonabelian 2generator group of order $\mathrm{p}^{3} \mathrm{q}$, where $\mathrm{p}$ and $\mathrm{q}$ are distinct primes and $\mathrm{p}<\mathrm{q}$. Then $\mathrm{G}$ is exactly one group of the following types Eq. 1-6:

$$
\begin{aligned}
& \mathrm{G}=<\mathrm{A}, \mathrm{Q} \mid \mathrm{A}^{8}=\mathrm{Q}^{\mathrm{q}}=1, \\
& \mathrm{~A}^{-1} \mathrm{QA}=\mathrm{Q}^{-1}>; \mathrm{q} \equiv 1(\bmod 2)
\end{aligned}
$$

Corresponding Author: Sarmin, N.H., Department of Mathematics, Faculty of Science and Ibnu Sina, Institute for Fundamental Science Studies, University Technology Malaysia, 81310 UTM Johor Bahru, Johor, Malaysia 
$\mathrm{G}=<\mathrm{A}, \mathrm{Q} \mid \mathrm{A}^{8}=\mathrm{Q}^{\mathrm{q}}=1, \mathrm{~A}^{-1} \mathrm{QA}=\mathrm{Q}^{\mathrm{a}}>$

where, $\mathrm{a}$ is any primitive root of $\mathrm{a} 4 \equiv 1(\bmod \mathrm{q}), \mathrm{q} \equiv 1$ $(\bmod 4)$ :

$\mathrm{G}=<\mathrm{A}, \mathrm{Q} \mid \mathrm{A}^{8}=\mathrm{Q}^{\mathrm{q}}=1, \mathrm{~A}^{-1} \mathrm{QA}=\mathrm{Q}^{\mathrm{a}}>$

where, a is any primitive root of $\mathrm{a} 8 \equiv 1(\bmod \mathrm{q}), \mathrm{q} \equiv 1$ $(\bmod 8)$ :

$\mathrm{G}=<\mathrm{A}, \mathrm{Q} \mid \mathrm{A}^{\mathrm{p} 3}=\mathrm{Q}^{\mathrm{q}}=1, \mathrm{~A}^{-1} \mathrm{QA}=\mathrm{Q}^{\mathrm{a}}>$

where, $a$ is any primitive root of ap $\equiv 1(\bmod q), q \equiv 1$ $(\bmod \mathrm{p})$ :

$\mathrm{G}=<\mathrm{A}, \mathrm{Q} \mid \mathrm{A}^{\mathrm{p} 3}=\mathrm{Q}^{\mathrm{q}}=1, \mathrm{~A}^{-1} \mathrm{QA}=\mathrm{Q}^{\mathrm{a}}>$

where, a is any primitive root of ap $2 \equiv 1(\bmod q), q \equiv 1$ $\left(\bmod \mathrm{p}^{2}\right)$ :

$\mathrm{G}=<\mathrm{A}, \mathrm{Q} \mid \mathrm{A}^{\mathrm{p} 2}=\mathrm{Q}^{\mathrm{q}}=1, \mathrm{~A}^{-1} \mathrm{QA}=\mathrm{Q}^{\mathrm{a}}>$

where, a is any primitive root of $a^{p 3} \equiv 1(\bmod q), q \equiv 1$ $\left(\bmod \mathrm{p}^{3}\right)$.

Theorem 5: Rashid et al. (2010) Let G be a nonabelian 2-generator group of order $\mathrm{p}^{3} \mathrm{q}$, where $\mathrm{p}$ and $\mathrm{q}$ are distinct primes and $\mathrm{p}<\mathrm{q}$. Then, $\mathrm{G}^{\prime} \cong \mathrm{C}_{\mathrm{q}}$, finite cyclic group of order q.

In this study, we focus on the derived subgroups of nonabelian 3-generator groups of order $\mathrm{p}^{3} \mathrm{q}$ where $\mathrm{p}$ and $\mathrm{q}$ are distinct primes and $\mathrm{p}<\mathrm{q}$.

The classification of all nonabelian 3-generator groups of order $\mathrm{p}^{3} \mathrm{q}$ is given in the following theorem.

Theorem 6: Western (1898) Let G be a nonabelian 3generator group of order $\mathrm{p}^{3} \mathrm{q}$, where $\mathrm{p}$ and $\mathrm{q}$ are distinct primes and $\mathrm{p}<\mathrm{q}$. Then $\mathrm{G}$ is exactly one group of the following types Eq. 7-21:

$$
\begin{aligned}
& \mathrm{G}=<\mathrm{A}, \mathrm{B}, \mathrm{Q} \mid \mathrm{A}^{4}=\mathrm{B}^{2}=\mathrm{Q}^{\mathrm{q}}=1, \\
& \mathrm{BAB}=\mathrm{A}^{-1}, \mathrm{AQ}=\mathrm{QA}, \mathrm{BQ}=\mathrm{QB}> \\
& \mathrm{G}=<\mathrm{A}, \mathrm{B}, \mathrm{Q} \mid \mathrm{A}^{4}=\mathrm{B}^{4}=\mathrm{Q}^{\mathrm{q}}=1, \\
& \mathrm{~B}^{2}=\mathrm{A}^{2} \mathrm{~B}^{-1} \mathrm{AB}=\mathrm{A}^{-1}, \mathrm{AQ}=\mathrm{QA}, \mathrm{BQ}=\mathrm{QB}> \\
& \mathrm{G}=<\mathrm{A}, \mathrm{B}, \mathrm{Q} \mid \mathrm{A}^{4}=\mathrm{B}^{2}=\mathrm{Q}^{\mathrm{q}}=1, \\
& \mathrm{AB}=\mathrm{BA}, \mathrm{AQ}=\mathrm{QA}, \mathrm{BQB}=\mathrm{Q}^{-1}>
\end{aligned}
$$

$$
\begin{aligned}
& \mathrm{G}=<\mathrm{A}, \mathrm{B}, \mathrm{Q} \mid \mathrm{A}^{4}=\mathrm{B}^{2}=\mathrm{Q}^{\mathrm{q}}=1, \\
& \mathrm{AB}=\mathrm{BA}, \mathrm{A}^{-1} \mathrm{QA}=\mathrm{Q}^{-1}, \mathrm{BQ}=\mathrm{QB}> \\
& \mathrm{G}=<\mathrm{A}, \mathrm{B}, \mathrm{Q} \mid \mathrm{A}^{4}=\mathrm{B}^{2}=\mathrm{Q}^{\mathrm{q}}=1, \\
& \mathrm{BAB}=\mathrm{A}^{-1}, \mathrm{AQ}=\mathrm{QA}, \mathrm{BQB}=\mathrm{Q}^{-1}> \\
& \mathrm{G}=<\mathrm{A}, \mathrm{B}, \mathrm{Q} \mid \mathrm{A}^{4}=\mathrm{B}^{2}=\mathrm{Q}^{\mathrm{q}}=1, \\
& \mathrm{BAB}=\mathrm{A}^{-1}, \mathrm{~A}^{-1} \mathrm{AQ}=\mathrm{Q}^{-1}, \mathrm{BQ}=\mathrm{QB}>\mathrm{q} \equiv 1(\bmod 2) \\
& \mathrm{G}=<\mathrm{A}, \mathrm{B}, \mathrm{Q} \mid \mathrm{A}^{4}=\mathrm{B}^{4}=\mathrm{Q}^{\mathrm{q}}=1, \\
& \mathrm{~B}^{2}=\mathrm{A}^{2}, \mathrm{~B}^{-1} \mathrm{AB}=\mathrm{A}^{-1,} \mathrm{AQ}=\mathrm{QA} \mathrm{B}^{-1} \mathrm{QB}=\mathrm{Q}^{-1}> \\
& \mathrm{G}=<\mathrm{A}, \mathrm{B}, \mathrm{Q} \mid \mathrm{A}^{4}=\mathrm{B}^{2}=\mathrm{Q}^{\mathrm{q}}=1, \\
& \mathrm{AB}=\mathrm{BA}, \mathrm{A}^{-1} \mathrm{QA}=\mathrm{Q}^{\mathrm{a}}, \mathrm{BQ}=\mathrm{QB}>
\end{aligned}
$$

where, $\mathrm{a}$ is any primitive root of:

$\mathrm{a}^{4} \equiv 1(\operatorname{modq})$ andq $\equiv 1(\bmod 4)$

$\mathrm{G}=<\mathrm{A}, \mathrm{B}, \mathrm{Q} \mid \mathrm{A}^{4}=\mathrm{B}^{4}=\mathrm{Q}^{3}=1, \mathrm{~B}^{2}=\mathrm{A}^{2}$,

$\mathrm{B}^{-1} \mathrm{AB}=\mathrm{A}^{-1}, \mathrm{Q}^{-1} \mathrm{AQ}=\mathrm{B}, \mathrm{Q}^{-1} \mathrm{BQ}=\mathrm{AB}>$

$\mathrm{G}=<\mathrm{A}, \mathrm{B}, \mathrm{Q} \mid \mathrm{A}^{4}=\mathrm{B}^{4}=\mathrm{Q}^{3}=1$,

$\mathrm{BAB}=\mathrm{A}^{-1}, \mathrm{Q}^{-1} \mathrm{~A}^{2} \mathrm{~B}=\mathrm{B}, \mathrm{A}^{-1} \mathrm{QA}=\mathrm{Q}^{2} \mathrm{~A}^{2} \mathrm{~B}>$

$\mathrm{G}=<\mathrm{A}, \mathrm{B}, \mathrm{Q} \mid \mathrm{A}^{\mathrm{p} 2}=\mathrm{B}^{\mathrm{p}}=\mathrm{Q}^{\mathrm{q}}=1$,

$\mathrm{B}^{-1} \mathrm{AB}=\mathrm{A}^{\mathrm{p}+1}, \mathrm{AQ}=\mathrm{QA}, \mathrm{BQ}=\mathrm{QB}>$

$\mathrm{G}=<\mathrm{A}, \mathrm{B}, \mathrm{Q} \mid \mathrm{A}^{\mathrm{p} 2}=\mathrm{B}^{\mathrm{p}}=\mathrm{Q}^{\mathrm{q}}=1$,

$\mathrm{AB}=\mathrm{BA}, \mathrm{AQ}=\mathrm{QA}, \mathrm{B}^{-1} \mathrm{Q} \mathrm{B}=\mathrm{Q}^{\mathrm{a}}>$

where, $\mathrm{a}$ is any primitive root of:

$\mathrm{a}^{\mathrm{p}} \equiv 1(\operatorname{modq})$ andq $\equiv 1(\bmod p)$

$\mathrm{G}=<\mathrm{A}, \mathrm{B}, \mathrm{Q} \mid \mathrm{A}^{\mathrm{p} 2}=\mathrm{B}^{\mathrm{p}}=\mathrm{Q}^{\mathrm{q}}=1$,

$\mathrm{AB}=\mathrm{BA}, \mathrm{A}^{-1} \mathrm{QA}=\mathrm{Q}^{\mathrm{a}}, \mathrm{BQ}=\mathrm{QB}>$

where, $\mathrm{a}$ is any primitive root of:

$\mathrm{a}^{\mathrm{p}} \equiv 1(\operatorname{modq})$ andq $\equiv 1(\bmod p)$

$\mathrm{G}=<\mathrm{A}, \mathrm{B}, \mathrm{Q} \mid \mathrm{A}^{\mathrm{p} 2}=\mathrm{B}^{\mathrm{p}}=\mathrm{Q}^{\mathrm{q}}=1$,

$\mathrm{B}^{-1} \mathrm{AB}=\mathrm{A}^{\mathrm{p}+1}, \mathrm{AQ}=\mathrm{QA}, \mathrm{B}^{-1} \mathrm{Q} \mathrm{B}=\mathrm{Q}^{\mathrm{b}}>$

where, $a$ is any primitive root of $\mathrm{a}^{\mathrm{p}} \equiv 1$ 
$(\operatorname{modq}), q \equiv 1(\bmod p)$ andb $=a, a^{2}, \ldots, a^{p-1}$

$\mathrm{G}=<\mathrm{A}, \mathrm{B}, \mathrm{Q} \mid \mathrm{A}^{\mathrm{p} 2}=\mathrm{B}^{\mathrm{p}}=\mathrm{Q}^{\mathrm{q}}=1$,

$\mathrm{AB}=\mathrm{BA}, \mathrm{A}^{-1} \mathrm{QA}=\mathrm{Q}^{\mathrm{a}}, \mathrm{BQ}=\mathrm{QB}>$

where, a is any primitive root of $\mathrm{a}^{\mathrm{p} 2} \equiv 1$ :

$(\operatorname{modq})$ andq $\equiv 1\left(\operatorname{modp}^{2}\right)$

\section{Main Result:}

Theorem 7: Let $G$ be a nonabelian 3-generator group of order $\mathrm{p}^{3} \mathrm{q}$, where $\mathrm{p}$ and $\mathrm{q}$ are distinct primes and $\mathrm{p}<$ q. Then $\mathrm{G}^{\prime} \cong \mathrm{C}_{2}, \mathrm{Cq}, \mathrm{C}_{2 \mathrm{q}}, \mathrm{C}_{\mathrm{p}}, \mathrm{C}_{\mathrm{pq}}, \mathrm{Q}_{8}$ or $\mathrm{A}_{4}$, where $\mathrm{Q}_{8}$, $\mathrm{A}_{4}$ are quaternion and alternating groups, respectively.

Proof: By Theorem 6, $\mathrm{G}$ has 15 types. If $\mathrm{G}$ is a group of type 6.1 , then $\mathrm{G}$ has three generators $\mathrm{A}, \mathrm{B}$ and $\mathrm{Q}$ and relations $\mathrm{BAB}=\mathrm{A}^{-1}, \mathrm{AQ}=\mathrm{QA}$ and $\mathrm{BQ}=\mathrm{QB}$. For this group we can obtain the following relations:

- $\quad \mathrm{A}^{\mathrm{i}} \mathrm{Q}^{\mathrm{j}}=\mathrm{Q}^{\mathrm{j}} \mathrm{A}^{\mathrm{i}} ;$ for all $\mathrm{i}, \mathrm{j} \in Z$

- $\quad B^{i} Q^{j}=Q^{j} B^{i}$; for all $i, j \in Z$

- $\mathrm{AB}=\mathrm{BA}^{-1}, \mathrm{~A}^{2} \mathrm{~B}=\mathrm{BA}^{2}, \mathrm{~A}^{3} \mathrm{~B}=\mathrm{BA}$

- $[\mathrm{A}, \mathrm{B}]=\mathrm{A}^{2},\left[\mathrm{~A}^{2}, \mathrm{~B}\right]=1$

Then by mentioned relations for all $\mathrm{x}, \mathrm{y} \in \mathrm{G},[\mathrm{x}, \mathrm{y}]$ $=1$ or $A^{2}$. Therefore, $G^{\prime}=\left\{1, A^{2}\right\}$, that is, $G^{\prime} \cong C_{2}$.

The proof of the second type is similar to the first type.

To compute the derived subgroup for a group of type 6.3, by relations $\mathrm{AB}=\mathrm{BA}, \mathrm{AQ}=\mathrm{QA}, \mathrm{BQB}=\mathrm{Q}^{-1}$ and $\left[\mathrm{Q}^{\mathrm{k}}, \mathrm{B}\right]=\mathrm{Q}^{-2 \mathrm{k}}$, we can obtain that $\mathrm{G}^{\prime} \cong \mathrm{C}_{\mathrm{q}}$.

The proof of types $6.4,6.8,6.12,6.13$ and 6.15 is similar to that type of 6.3 .

For type $6.5, \mathrm{G} \cong \mathrm{D}_{4 \mathrm{q}}$, then $\mathrm{G}^{\prime} \cong \mathrm{C}_{2 \mathrm{q}}$.

Let $\mathrm{G}$ be a group of type 6.6 , then by relation $\mathrm{A}^{-1}$ $\mathrm{AQ}=\mathrm{Q}^{-1}$ it is clear that $\left|\mathrm{G}^{\prime}\right| \geq \mathrm{pq}$ and relation, $\mathrm{BAB}=$ $\mathrm{A}^{-1}$ shows that $1, \mathrm{~A}^{2} \in \mathrm{G}^{\prime}$. Thus $\left|\mathrm{G}^{\prime}\right|=2 \mathrm{q}$ and $\mathrm{G}^{\prime} \cong<\mathrm{BQ}$ $>$, that is, $\mathrm{G}^{\prime} \cong \mathrm{C}_{2 \mathrm{q}}$.

For proving 6.7 , we can use the method that we used in type 6.6.

For a group of type $6.9, \mathrm{G} \cong \mathrm{SL}(2,3)$, where $\mathrm{SL}$ $(2,3)=<a, b, c \mid a^{3}=b 3=c^{2}=a b c>$. So $G^{\prime} \cong Q_{8}$.

To compute $\mathrm{G}^{\prime}$ for a group of type 6.10 , by the number of generators and relations it is an immediate consequence that $\mathrm{G} \cong \mathrm{S} 4$. Therefore, $\mathrm{G}^{\prime} \cong \mathrm{A}_{4}$.

Let $\mathrm{G}$ be a group of type 6.11 , then relations $\mathrm{A}^{\mathrm{p} 2}=$ $\mathrm{B}^{\mathrm{p}}=\mathrm{Q}^{\mathrm{q}}=1, \mathrm{~B}^{-1} \mathrm{AB}=\mathrm{A}^{\mathrm{p}+1}, \mathrm{AQ}=\mathrm{QA}, \mathrm{BQ}=\mathrm{QB}$ show that $\mathrm{G}^{\prime}$ is isomorphic to $\mathrm{C}_{\mathrm{p}}$.
Finally, for a group of type 6.14 , the relations $\mathrm{A}^{\mathrm{p} 2}$ $=\mathrm{B}^{\mathrm{p}}=\mathrm{Q}^{\mathrm{q}}=1, \mathrm{~B}^{-1} \mathrm{AB}=\mathrm{A}^{\mathrm{p}+1}, \mathrm{AQ}=\mathrm{QA}$,

$\mathrm{B}^{-1} \mathrm{Q} B=\mathrm{Q}^{\mathrm{b}}$ show that $\left|\mathrm{G}^{\prime}\right|=\mathrm{pq}$ and by computing the commutators, $\mathrm{G}^{\prime}$ is a cyclic group of order pq. $\square$

\section{REFERENCES}

Burnside, W., 1911. Theory of Groups of Finite Orde. 2nd Edn., The University Press, Cambridge, pp: 512.

Hungerford, T.W., 1997. Abstract Algebra: An introduction. 2nd Edn., Saunders College Publishing, Philadelphia, ISBN-10: 0030105595 pp: 588.

Miller, G.A., 1898. On the Commutator Groups. Bull. Amer. Math. Soc., 4: 135-139.

Rashid, S., N.H. Sarmin, A. Erfania and N.M. Mohd Ali, 2010. The commutator subgroups of groups order of p3q. Proceedings of the RAFSS, (RAFSS' 10), pp: 492-495.

Western, A.E., 1898. Groups of order p3q, Proc. London Math. Soc., 30: 209-263. DOI: 10.1112/plms/s1-30.1.209 